DOI 10.37882/2223-2982.2021.06.40

\title{
ТОПОНИМИЧЕСКИЙ ОБРАЗ В ЗЕРКАЛЕ ЧУЖОЙ КУЛЬТУРЫ: ЭКСПЕРИМЕНТАЛЬНОЕ ИССЛЕДОВАНИЕ
}

\section{TOPONYMIC IMAGE IN THE MIRROR OF A FOREIGN CULTURE: AN EXPERIMENTAL STUDY}

Yue Qu

Summary: This article is devoted to the description and identification of toponymic images in the minds of native Chinese speakers using an associative onomastic experiment based on the material of Moscow urbanonyms. The relevance of the research is determined by the tasks of adequate assimilation of Russian toponymy in its linguistic, linguocultural and geocultural aspects. The degree of distortion of the Moscow urbanonym image revealed in our associative experiment, and the linguistic and cultural analysis of the reasons for this quasi-identification, will be a useful hint for choosing the necessary motivational features that characterize the toponym in the training toponymic database we are developing - a new type of educational tool designed to form the necessary skills and abilities of foreign communicants to adequately identify elements of the Russian geocultural space.

Keywords: urbanonym, toponymic image, associative experiment, geocultural space, quasi-identification, training toponymic database.

\author{
Юе Цюй \\ Аспирант, Институт языкознания РАН \\ yuequ0726@yandex.com
}

Аннотация: Статья посвящена описанию и выявлению топонимических образов в сознании носителей китайского языка с помощью ассоциативного ономастического эксперимента на материале московских урбанонимов. Актуальность исследования обусловлена задачами адекватного усвоения русской топонимии в ее языковом, лингвокультурном и геокультурном аспектах. Степень искажения образа московского урбанонима, выявленная в проведенном нами эксперименте, и лингвокультурологический анализ причин такой квази-идентификации, станут полезной подсказкой для выбора необходимых мотивационных признаков, характеризующих топоним в разрабатываемой нами обучающей топонимической базе данных - учебном инструменте нового типа, предназначенном для формирования у иностранных коммуникантов необходимых навыков и умений адекватной идентификации элементов русского геокультурного пространства.

Ключевые слова: урбаноним, топонимический образ, ассоциативный эксперимент, геокультурное пространство, квази-идентификация, обучающая топонимическая база данных.

\section{Введение}

$\mathrm{y}$ рбаноним представляет собой вид топонима, это собственное имя (СИ) любого внутригородского топографического объекта, ср. [10, с. 139]. Главная функция урбанонимов - номинация объекта и ориентация в городском пространстве, т.е. функции номинативная и адресная. В реальной коммуникации названия улиц, площадей, отдельных зданий и других объектов в городе получают дополнительные функции прагматического и символического характера, выражающие отношение к ним говорящих. Об антропоцентричности топонимической номинации в настоящее время пишут ученые, работающие в области топонимики и этнолингвистики [1]. Топонимические исследования активно включаются в приоритетные научные направления, отвечающие «целям и задачам антропоцентрической лингвистики, лингвистики текста и когнитивно-дискурсивной (коммуникативной) парадигмы научного знания» [8, с. 28]. Одним из важных методов изучению топонимов также является психолингвистический подход. В русле психолингвистических исследований СИ интерпретируется как вербально-семиотическое средство отражения когнитивной деятельности человека, его мировоззрения и миропонимания. Ассоциативный эксперимент, точнее, интерпретация его результатов, дает возможность выявить и описать психолингвистическое значение слова - «упорядоченное единство всех семантических компонентов, которые реально связаны с данной звуковой оболочкой в сознании носителей языка» [14, с.112]. Ассоциативный эксперимент как хорошо разработанный способ изучения языкового сознания в психолингвистике является в нашем исследовании важным для решения проблем межкультурной коммуникации, поскольку он предоставляет возможность ознакомления с топонимическим знанием, усвоенным и используемым носителями другого языка и культуры при идентификации топонимической лексики в речи.

Еще одним направлением, идеи которого проникают в традиционные топонимические исследования последних десятилетий, является гуманитарная географии. Существующая в ее рамках имажинальная, или образная, география изучает особенности формирования образа места (территории), который представляет собой комплекс представлений (знаков, символов, архетипов, «картинок», ассоциаций, стереотипов и др.), характеризующих в сознании человека (людей) конкретную территорию [6, с. 657]. В гуманитарной географии топонимы считаются доминантными элементами геокультурного 
пространства, которые выступают не только как носители географической информации в пространствовременных параметрах, но и как носители смыслов и воплощения значения [7, с. 43]. Оперируя понятием топонимического образа, ученые в области ономастики разработали понятие топонимического имиджирования в качестве обновленного подхода к конструированию и репрезентации образа (имиджа) территории [4]. В нашем исследовании мы предлагаем ввести понятие топонимического образа (имиджа) в сферу межкультурной коммуникации. Это понятие будет служить характеристикой лингвокультурной информации, транслируемой топонимом, которая возникает у носителей другого языка и другой культуры. Под топонимическим образом (имиджем) мы понимаем субъективные представления о месте (топосе), которые складываются в сознании языковой личности, овнешняются в топонимических знаках и имеют определенное ассоциативное соотношение с объективной реальностью.

\section{Топонимический образ в сознании носителя чужкой культуры}

Интерес к изучению топонимического образа в сознании чужой культуры обусловлен задачами формирования у иностранных учащихся навыков для адаптации к российскому геокультурному пространству через усвоение топонимической лексики и локальной культуры, стоящей за словом. В последние несколько десятилетий проблемы правильного понимания и полного усвоения русской топонимии иностранными учащимися нашли отражение в научных работах, посвященных преподаванию топонимической лексики в сфере обучения РКИ, ср. [11], [16], [12], [9] и др.

Современная педагогическая стратегия особо акцентирует внимание на взаимодействии «язык и человек». Эта стратегия направлена на формирование у изучающих иностранный язык способности производства и восприятия речевых произведений, приближенной к возможностям тех, для кого данный язык является родным. Руководствуясь этим принципом, мы полагаем, что для решения проблемы топонимической идентификации следует сформировать у иностранных учащихся топонимические образы, приближенные к геокультурному пространству изучаемого языка.

В рамках настоящей статьи ставится задача описания топонимических образов в сознании носителей китайского языка. Проводится анализ языковых и культурных факторов, обусловливающих появления искажения образов места в сознании носителей чужой культуры. В дальнейшем предполагается построение топонимической базы данных обучающего типа в качестве коммуникативного и учебного инструмента для реализации проблемы топонимической идентификацией.
В процессе исследования используется тип ассоциативного ономастического эксперимента ограниченного формата, в котором в качестве стимулов выступают только СИ [2, с. 130]. Небольшой свободный ассоциативный эксперимент в малых группах испытуемых, хотя не сможет полностью раскрыть топонимическую картину мира в чужих глазах, тем не менее обладает достаточной репрезентативностью, для того чтобы продемонстрировать искажения образов сознания при восприятии чужих объектов и различия двух видов локальных культуры и ментальных стереотипов (ср., например, эксперимент с английскими СИ в русской аудитории [16]). Наш эксперимент проводился на материале московских урбанонимов, форма которых в словообразовательном и мотивационном отношении достасточно типична для славянских топонимов, и эти урбанонимы представляют знаковые места столицы России, что является важным для презентации их иностранным коммуникантам в кросс-культурном контексте.

\section{Прочесс исследования}

Ассоциативный эксперимент был проведен с 23 китайскими студентами, владеющими РКИ. Им была поставлена достаточно простая задача: написать первое пришедшее в голову слово или словосочетание на следующие стимулы-топонимы: Китай-город, Воробьевы горы, Измайлово, Красная площадь. Результаты исследования приводятся ниже по следующей схеме:

Kumaŭ-город: Китай (10), Пекин (5), Гуанчжоу (2), Цюаньчжоу(1), Санья (1), Хэнань(1), Китайская еда (1), Сильный (1), пустой ответ (1)

Воробъевы горы: Воробей (12), МГУ (4), станция МГУ (1), красивый (1), листопад (1), не знает (4).

Измайлово: один Муравей (8), ярмарка (4), не знает (4), матрешка (1), удаленный (1), экзотический (1), фамилия (1), интересное место (2), столица (1)

Красная площадь: площадь красного цвета (14), красный (1), Собор Василия Блаженного (2), красивый (1), шумный (1), море людей (1), посещать (1), Москва (1), не знаю (1).

Анализ ассоциатов на слова-стимулы проводился в системно-языковом и прагматическо-когнитивном планах, ср. схему [13]. Системно-языковой анализ представляется следующим образом. Видно, что на лексико-синтаксическом уровне большинство испытуемых не умеет построить грамматически правильные синтаксические связи между реакцией и стимулами, это особо проявляется в неумении согласования родового слова и топонима в предложении: ср. Красная площадь (шумный 1, красивый 1), Измайлово (удаленный 1, экзотический 1), Воробьевы горы (красивый 1). 
На семантико-мотивационном уровне лишь один испытуемый ассоциирует стимул с его мотивационной базой, см. Измайлово (фамилия 1). Также наблюдаются примеры искаженной ассоциации мотивационной связи заданного стимула с его исходным апеллятивом, см. Китай-город (Китай 10), Воробьевы горы (Воробей 12). В целом, в сознании испытуемых не выстроена системная категоризация мотивационных связей заданных урбанонимов с их производящими основами.

На лексическом уровне выделяется парадигматическая ассоциация, отражающая родовое и видовое отношение между стимулами и другими видами онимов: ср. Воробьевы горы (МГУ 5), Измайлово (столича 1), Красная площадь (Собор Василия Блаженного 2, Москва 2). Однако данное отношение занимает небольшую долю в ассоциативном поле стимула.

На фонетическом уровне интересной представляется ассоциация Измайлово с животным муравей. В сознании носителей китайской языка она обусловлена схожестью фонетической транскрипции данного урбанонима на китайском языке. Случайное совпадение звучания русского слова с его транскрипцией на китайском языке легко приводит к вызыванию у испытуемых квази-ассоциаций из-за взаимодействия двух систем в речемыслительной и аудиально-произносительной деятельности коммуникантов.

Когнитивно-прагматический анализ ориентируется на описание сохраняемого в сознании носителей другой культуры топонимического знания и выявление их субъективных отношений к стимулам. При восприятии урбанонимов у испытуемых легко вызывается ассоциация с релевантными локальными объектами, что обусловлено онтологической детерминированностью топонимической системы. Как отмечают Н.Д. Голев и Л.М. Дмитриева, «восприятие каждого названия сопровождается ассоциациями, но в отличие от апеллятивной лексики топонимы обрастают ассоциациями, осложненными привязкой топонима к местности - пространству» [3, с. 11]. Наряду с этим, объемность и содержание топонимической информации, усвоенной испытуемыми, зависит от их собственных перцептивных и концептуальных знаний о топониме-стимуле и номинируемом объектом. При восприятии хорошо знакомых урбанонимов у испытуемых легко возникают ассоциации с элементами, лежащими в данной локальной культуре, например, Воробьевы горы и Красная площадь пользуются широкой популярностью у китайских испытуемых, соответственно, испытуемым совсем не трудно связать стимул с символическими постройками, расположенными в этом месте. При восприятии малознакомых урбанонимов топонимические образы с очевидностью отклоняются от русского лингвокультурного и геокультурого пространства. Например, большинство испытуемых идентифицирует урбаноним Китай-город со своей родной геокультурой: ср. Китай- город (Китай 10, разные китайские города 10). Те, кто не имеют достаточно фоновых знаний о месте Измайлово, считают, что данный урбаноним не входит в сферу их локальной культуры, и описывают свое ощущение такими атрибутами, как удаленный (1), экзотический (1).

Когнитивно-прагматический анализ реакций показывает, что топонимические образы, локализованные в сознании носителей китайского языка, достаточно ограничены и не совсем адекватны российскому геокультурному пространству. В некоторых случаях даже возникает квази-идентификация урбанонимов, ср. Китай-город (Китай и другие китайские города), Измайлово (один муравей). В совокупности слов-реакций можно найти мало культурно-символических элементов, характерных для русской локальной культуры, их можно считать обладающими периферийными признаками в языковом сознании китайских испытуемых. Это такие историкокультурные реалии, как матрешка, МГУ, собор Василия Блаженного. Доминирующими стереотипными представлениями о московских урбанонимах у них являются «место для посещения», «интересное, красивое место», «место на удаленке». В целом можно констатировать, что в сознании китайских испытуемых не создана целостная и полная картина локальной культуры Москвы, зафиксированной в московских урбанонимах.

Возникновения разных топонимических образов у испытуемых обусловлено тем, что актуализация топонимов в сознании человека носит наивно-эгоцентричный характер, результаты познания человеком мира отражают, прежде всего, жизненный и деятельностный опыт языковой личности. В межкультурной коммуникации ассоциативные значения, связанные с словами-стимулами, представляют собой фрагменты, извлеченные из памяти индивида и носящие следы его речемыслительной и коммуникативной деятельности в иноязычном прагматическом контексте. Различные образные схемы, сформированные в сознании китайских испытуемых, определяются разнообразием человеческого опыта при соприкосновении с данным топонимом. Закономерно при этом, что чем обильнее количество накопленных знаний о воспринимаемом топониме в сознании носителей другой культуры, тем сильнее их представления приближается к русскоязычному геокультурному пространству.

В межкультурной коммуникации непонимание или недопонимание речевых смыслов обусловлено искажением образов сознания в их овнешнениях между носителями своей и чужой лингвокультур [14]. Восприятие мира человеком постоянно подвергнуто воздействию идиокультурных стереотипов мышления, что составляет особые трудности для формирования лингвокультурно и лингвокогнитивно идентифицированных образов у носителей чужой культуры. Например, соотнесение ур- 
банонима Китай-город с китайскими локальными объектами связано с ностальгическими переживаниями, сформированными в виде устойчивых стереотипов в китайской культуре, которые имеют эмоционально-аффективную силу пробуждения у носителей языка сильной привязанности и любви к своей родине при восприятии чужой географической номинации. Таким образом, квази-идентифицированный образ города, представленный в сознании носителей китайской культуры, отражает именно стереотипы-представления, присущие китайской наивной картине мира.

\section{Топонимическая база Аанных как способ передачи топонимического знания в межкультурной коммуникашии}

В настоящее время, благодаря стремительному развитию информационно-коммуникативной технологий, создание электронного топонимического ресурса как актуальное прикладное направление изучения ономастики [5], открывает иностранным учащимся новую возможность для полного усвоения чужой топонимической лексики. Топонимическая база данных представляет собой один из технических способов полного свода, обработки и представления топонимического знания. В обучающую базу данных открытого типа, разрабатываемую нами на материале московских урбанонимов для носителей китайского языка, не только включаются лингвистические классификации по группам структурно-языковых признаков, но и выделяется специальное поле лингвокультурной информации для репрезентации геокультурной и этнокультурной специфики изучаемого языка и усваиваемой территории. В основе пред- ставления лингвокультурной информации для топонима в иноязычной аудитории лежит обсуждаемое в настоящей статье понятие топонимического образа. Формирование адекватных топонимических образов в конечном счете является той целью, с которой создается база данных обучающего типа.

\section{Заключение}

Проведенный нами ассоциативный эксперимент по выявлению топонимических образов в сознании носителей китайского языка показал, что у большинства испытуемых не сформировалось способности к адекватной интерпретации семантического содержания русскоязычного топонима. Топонимические образы, представленные в сознании испытуемых, характеризуется значительно ограниченной информативностью. Поскольку урбанонимы представляют собой важные источники лингво- и геокультурной информации в городском пространстве, формирование у иностранных учащихся лингвокультурно идентичных топонимических образов можно считать важной предпосылкой для адекватного усвоения городской топонимической культуры страны изучаемого языка. Как показало наше исследование, эффективным инструментом в этом случае является ассоциативный эксперимент, с помощью которого выявляются все «слабые звенья» в интерпретации топонимического образа иностранными коммуникантами. Следующая ступень состоит в формировании необходимых сементико-мотивационных признаков, позволяющих в дальнейшем избежать неадекватной лингвокультурной интепретации топонима как элемента геокультурного пространства.

\section{ЛИТЕРАТУРА}

1. Березович Е.Л. Русская топонимия в этнолингвистическом аспекте: Пространство и человек. Изд. 2, испр. и доп. М.: Книжный дом «ЛИБРОКОМ», 2009.328 с.

2. Васильева Н.В. Заметки о психоономастике // Вопросы психолингвистики. 2014. №20. С. 128-137.

3. Голев Н.Д. Единство онтологического и ментального бытия топонимической системы (к проблематике когнитивной топонимики) / Н.Д. Голев, Л.М. Дмитриева // Вопросы ономастики. 2008. № 1 (5). с. 5-17.

4. Голомидова М.В. Топонимическое имиджирование городских пространственных объектов // Вопросы ономастики. 2020. Т. 17. № 3. С. $263-278$.

5. Гордова Ю.Ю. Актуальные способы обработки и представления ономастических данных: 2009 - 2019. М.: ЛЕНАНД, 2020. 128 С.

6. Замятин Д.Н. Геокультурный брендинг городов и территорий. СПб.: Алетейя, 2020.668 с.

7. Корнев И.Н. География и топонимика в контексте гуманитарного дискурса // Географический вестник. 2014. №1 (28). 41-45.

8. Корнева В.В. Топонимические исследования в новой научной парадигме // Вестник ВГУ. Серия: Лингвистика и межкультурная коммуникация. 2016. №1. 150-154.

9. МарТЫНЕНКО Ю.Б. СИСТЕМА РАБОТЫ С АНТРОПОНИМАМИ НА ЗАНЯТИЯХ ПО РУССКОМУ ЯЗЫКУ КАК ИНОСТРАННОМУ (НА МАТЕРИАЛЕ НАЗВАНИЙ СТАНЦИЙ МОСКОВСКОГО МЕТРО) // Вестник РГГУ. Серия «Психология. Педагогика. Образование». 2020. №3. 87-95.

10. Подольская Н.В. Словарь русской ономастической терминологии. Изд. 2-е, перераб. и доп. М.: Наука, 1988. 192 с.

11. Позднякова А.А., Джахит Хамуркопаран. Работа с топонимической лексикой на занятиях по русскому языку как иностранному // Преподаватель XXI век. 2015. №3. 170-180.

12. Рощектаева Т.Г. Изучение топонимов на начальном этапе обучения русскому языку как иностранному (на материале учебного пособия С.А. Хаврониной и А.И. Широченской «Русский язык в упражнениях») // Русистика. 2014. №1. 49-53.

13. Стернин И.А. Проблемы интерпретации результатов ассоциативных экспериментов // Вопросы психолингвистики. 2020. №. 3 (45). С. 110-125.

14. Тарасов Е.Ф. - Тарасов Е.Ф. Введение // Язык и сознание: парадоксальная рациональность. М., 1996. С. 6-15. 
15. Чернобров А.А. 0 достоинствах и недостатках количественных эмпирических методов в лингвистике (Обзор ассоциативных экспериментов с собственными именами за 1993-1999 гг.) [Электронный ресурс]. URL: http://imena.org/name_exp. html (дата обращения: 20.08.2019).

16. Щербакова 0.М. Топонимическая лексика в курсе русского языка как иностранного // Полилингвиальность и транскультурные практики. 2014 . №1. 87-90.

○ Юе Цюй (yuequ0726@yandex.com).

Журнал «Современная наука: актуальные проблемы теории и практики»

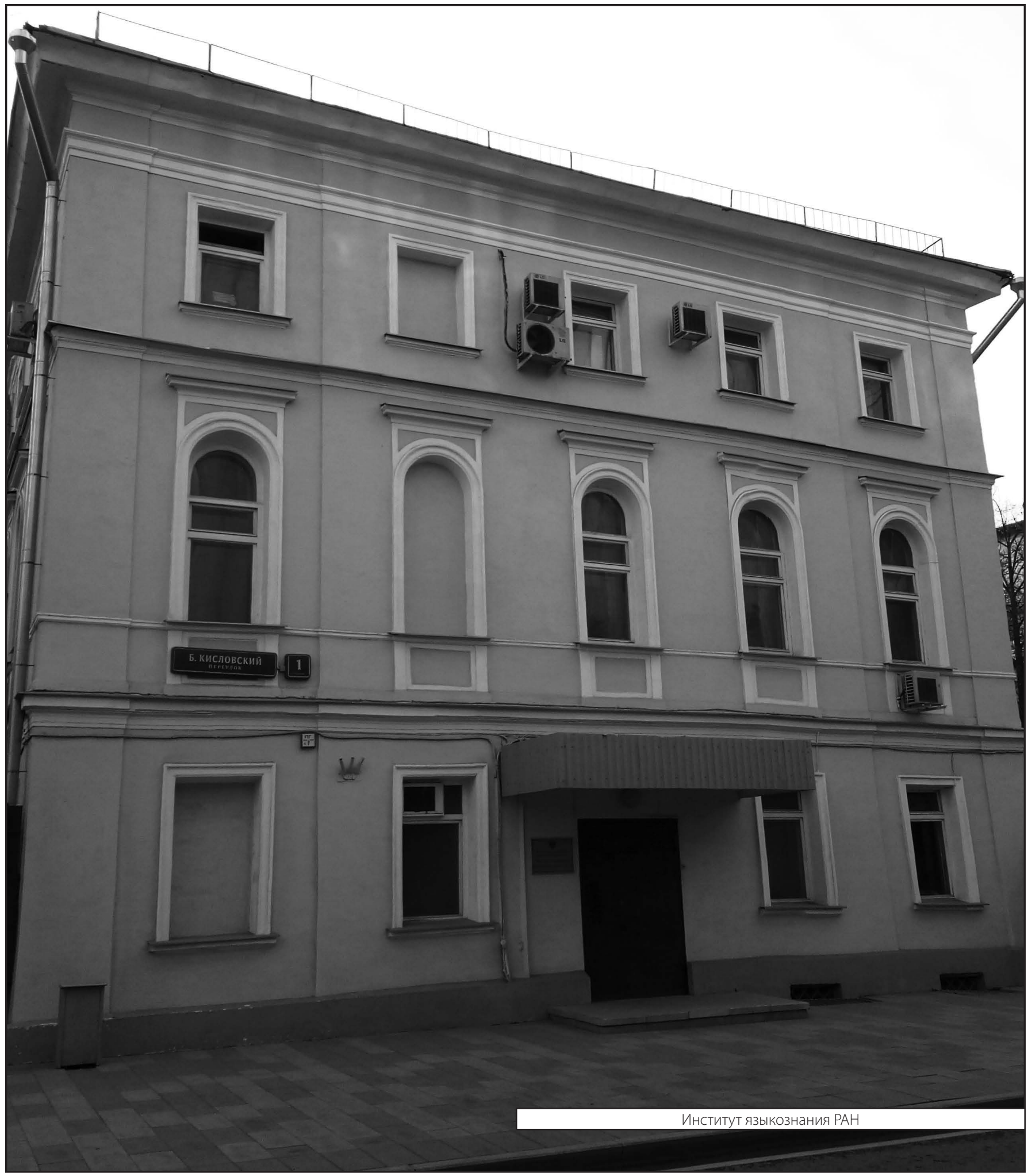

